\title{
Uncertainty and Monetary Policy Rules in the United States
}

\author{
Christopher Martin \\ Department of Economics and Finance, \\ Brunel University \\ Uxbridge \\ Middlesex UB8 3PH \\ and \\ Costas Milas \\ Department of Economics, \\ Keele University \\ Staffordshire, ST5 5BG
}

November 2005

\begin{abstract}
This paper analyses the impact of uncertainty about the true state of the economy on monetary policy rules in the US since the early 1980s. Extending the Taylor rule to allow for this type of uncertainty, we find evidence that the predictions of the theoretical literature on responses to uncertainty are reflected in the behaviour of policymakers, suggesting that policymakers are adhering to prescriptions for optimal policy. We find that the impact of uncertainty was most marked in 1983, when uncertainty increased interest rates by up to 140 basis points, in 1989-90, when uncertainty increased interest rates by up to 50 basis points and in 1996-2001 when uncertainty reduced interest rates by up to 50 basis points over five years.

JEL: C51; C52; E52; E58

Keywords: monetary policy, uncertainty

Corresponding author: Costas Milas, Department of Economics, Keele University, Keele, ST5 5BG, United Kingdom.

Phone: +44 (0) 1782 583090. Fax: +44 (0) 1782 717577. Email: c.milas@keele.ac.uk

We thank seminar audiences at Brunel, Cambridge and Loughborough Universities and at Cass Business School for their comments.
\end{abstract}




\section{Uncertainty and Monetary Policy Rules in the United States}

"Uncertainty is not just an important feature of the monetary policy landscape; it is the defining characteristic of that landscape" (Greenspan, 2003).

\section{1) Introduction}

Uncertainty is a central issue in monetary policy, as the quote from Alan Greenspan above illustrates. Empirical models, however, rarely take account of this, effectively assuming that policymakers ignore uncertainty. The evident focus of policymakers on uncertainty suggests that this assumption is invalid and therefore that empirical models of monetary policy must account for uncertainty. This paper considers the effects of uncertainty about the true state of the economy on monetary policy, estimating a monetary policy rule that allows for this.

Our empirical model draws on the theoretical literature on optimal monetary policy when there is uncertainty about the true state of the economy, most prominently Svensson and Woodford (2003, 2004) and Swanson (2004). In existing models of monetary policy under certainty, monetary policy affects inflation and the output gap directly, so it is optimal for policymakers to use these variables in forming monetary policy. This is the basis for the Taylor rule (Taylor, 1993) model of monetary policy and its' subsequent refinements (eg Woodford, 2003). The literature on monetary policy under uncertainty assumes instead that monetary policy affects the state of the economy, which in turn affects inflation and the output gap. It is then optimal for monetary policy to respond to the state of the economy. However, it is assumed that the state of the economy is 
unobserved and that policymakers must infer this from observations of inflation and the output gap. Optimal monetary policy is a certainty equivalent function of the expected state of the economy. The expected state of the economy is in turn a linear function of inflation and the output gap, whose parameters are functions of the variances of these variables.

The resultant optimal monetary policy rule resembles the familiar Taylor rule (Taylor, 1993), but where the coefficients are functions of the variances of inflation and the output gap. These apparent departures from certainty equivalence arise because of the role of inflation and the output gap as indicator variables for monetary policy. An increase in, for example, the variance of inflation reduces the parameter on inflation and increases the parameter on the output gap in the equation for the expected state of the economy. This leads to a smaller weight on inflation and a larger weight on the output gap in the monetary policy rule. Similarly, an increase in the variance of the output gap reduces the weight on the output gap and increases the weight on inflation in the equation for the expected state of the economy, resulting in a lower weight on the output gap and a corresponding larger weight on inflation. As a result, the model makes two main testable predictions. First, policymakers should respond less vigorously to variables that are more uncertain, so the weight on inflation in the policy rule should be lower when inflation is more uncertain and similarly for the output gap (cf Peersman and Smets, 1999, Rudebusch, 2001, Soderstrom, 2002, Smets, 2002, Srour, 2003, Walsh, 2004 and Swanson, 2004). Second, uncertainty about one variable may strengthen the response to the other variable, so the weight on 
the output gap may be larger when inflation is less certain, and vice versa (cf Peersman and Smets, 1999, and Swanson, 2004).

We estimate a system of equations, comprising a monetary policy rule whose parameters are functions of the variances of inflation and the output gap and equations for inflation and the output gap whose error terms have GARCH processes, from which these variances are derived. We use data since 1983 since this is when the Fed switched to using the interest rate as the tool of monetary policy and since continuity in monetary policy objectives has allowed stable policy rules to be estimated over this period (eg Judd and Rudebusch, 1998). We find that the behaviour of monetary policymakers is consistent with the predictions of the theoretical literature. Monetary policy responds less to inflation and the output gap when these variables are more uncertain. We also find that the response to inflation is stronger when the output gap is more uncertain, and vice versa. We quantify the impact of uncertainty by constructing a measure of the counterfactual interest rate, which would have been observed if there had been no uncertainty. We find that the impact of uncertainty was most marked in 1983 , when uncertainty increased interest rates by up to 140 basis points, 1989-90, when uncertainty increased interest rates by up to 50 basis points and in 1996-2001 when uncertainty reduced interest rates by up to 50 basis points over five years.

The remainder of the paper is structured as follows. Section 2 explains our methodology. Section 3 presents our estimates. Section 4 summarizes our findings and offers some conclusions. 


\section{2) Methodology}

Our empirical model is based on theoretical contributions by Svensson and Woodford $(2003,2004)$ and Swanson (2004). We consider the model

$$
\pi_{t}=\pi_{t-1}+\theta_{\pi} y_{t-j}+v_{t}
$$

$$
y_{t}=X_{t} \beta+\gamma(L) y_{t-1}+\eta_{t}
$$

$$
X_{t}=\alpha_{0}-\alpha r_{t-k}+\varepsilon_{t}
$$

$$
i_{t}=i^{*}+\rho_{\pi t}\left(E_{t} \pi_{t+p}-\pi^{*}\right)+\rho_{y t} E_{t} y_{t+q}
$$

where $\pi$ is the inflation rate, $\pi^{*}$ is the inflation target (or desired rate of inflation), $y$ is the output gap, $X$ is the state of the economy (e.g. an index of inflationary pressures or an index of excess demand $)^{1}, i$ is the nominal interest rate, $i^{\star}$ is the equilibrium nominal interest rate, $r$ is the real interest rate (defined as $\left.r_{t}=i_{t}-E_{t} \pi_{t+1}\right)$ and $L$ is the lag operator. The integers $j, k, p$ and $q$ can be positive, negative or zero, so that the relationships in equations (1)-(4) can be backward-looking, forward-looking or contemporaneous.

This model is similar to that considered by Swanson (2004) and comparable to that of Svensson and Woodford $(2003,2004)$. Equation (1) is a

\footnotetext{
${ }^{1}$ Although we treat $X$ as a scalar for simplicity, in general it may have many elements; see Swanson (2004).
} 
Phillips curve in which inflation at time $t$ is affected by lagged inflation and by the output gap at time $(t-j)$. Equation (2) is an aggregate demand equation in which the output gap is affected by the state of the economy. Equation (3) describes how the state of the economy at time $t$ is affected by the real interest rate at time $(t-k)$. Finally, equation (4) is a policy rule in which interest rates respond to the expected gap between inflation and the target $p$ periods ahead and to the expected output gap $q$ periods ahead. We model uncertainty about inflation and the output gap by assuming that the error terms in their respective equations follow $\operatorname{GARCH}(1,1)$ processes. Specifically, $v_{t}$ is a shock to inflation, assumed to be distributed as $N\left(0, \sigma_{\pi t}^{2}\right)$, where $\sigma_{\pi t}^{2}=\omega_{0}+\omega_{1} v_{t-1}^{2}+\omega_{2} \sigma_{\pi t-1}^{2}$ and $\omega_{0}, \omega_{1}$ and $\omega_{2}$ are parameters. $\eta$ is a shock to the output gap, assumed to be distributed as $N\left(0, \sigma_{\eta t}^{2}\right)$, where $\sigma_{\eta t}^{2}=\lambda_{0}+\lambda_{1} \eta_{t-1}^{2}+\lambda_{2} \sigma_{\eta t-1}^{2}$ and $\lambda_{0}, \lambda_{1}$ and $\lambda_{2}$ are parameters. $\varepsilon$ is a shock to the state of the economy, assumed to be distributed as $N\left(0, \sigma_{\varepsilon}^{2}\right)$. We use the implied variances of $v$ and $\eta$ to measure uncertainty about inflation and the output gap respectively (for a similar approach, see Grier and Perry, 2000). Policymakers are assumed to know all parameters of the model and the history of all variables save for the state of the economy, which is always unknown.

Swanson (2004) considers a model with simultaneous macroeconomic relationships (similar to equations (1)-(3) when $j=k=0$ ). Assuming policymakers have quadratic preferences, he establishes that a policy rule similar to (4) is optimal when $p=q=-1$; he also shows that $\rho_{\pi t}$ is decreasing and $\rho_{y t}$ is increasing in $\sigma_{\pi t}^{2}$, the variance of the inflation equation, while $\rho_{\pi t}$ is increasing 
and $\rho_{y t}$ is decreasing in $\sigma_{\eta t}^{2}$, the variance of the output gap equation. The policy rule does not satisfy the certainty-equivalence principle since the weights on the monetary policy rule are functions of the variances of the output gap and inflation equations. If known, the optimal monetary policy rule would be a simple function of the state of the economy that satisfies certainty equivalence. Since it is not, policymakers use observations of inflation and the output gap as indicator variables, in effect predicting the state of the economy using a linear function of inflation and the output gap, whose coefficients are functions of the variances of equations (1) and (2). Changes in these variances therefore change the parameters of the monetary policy rule in (4), breaking certainty equivalence. Extending Swanson's results to cases with forward-looking variables is difficult ${ }^{2}$ and we cannot as yet make claims about the optimality properties of (4) in the forward-looking case (although Svensson and Woodford, 2003, 2004, have made some progress on this) ${ }^{3}$. Nonetheless we conjecture that Swanson's argument can be extended to the forward-looking case and will use the policy rule in (4) as the basis of our empirical model ${ }^{4}$.

\footnotetext{
2 Svensson and Woodford (2003, pp 692-693) note that in this case "the problem ....is inherently more complicated" because "forward-looking variables..depend..on..expectations of future endogenous variables and of current and future policy actions. However these expectations in turn depend on an estimate of the current state of the economy, and that estimate depends, to some extent, on observations of the current forward-looking variables. This circularity presents a considerable challenge".

${ }^{3}$ Svensson and Woodford's (2003, p 693) finding that in a forward-looking model "when the degree of noise in an indicator of potential output is large, the optimal weight on that indicator becomes small" is similar to Swanson (2004)'s results.

4 The policy rule in (4) has parallels with Brainard's (1967) model of uncertainty about the parameters of macroeconomic relationships. In that case, the optimal monetary policy rule is similar to (4) but where the weights on inflation and the output gap are functions of the variances of the uncertain parameters.
} 
The policy rule in (4) is a simple extension of the Taylor rule representation of monetary policy rules (Taylor, 1993). Following the influential work of Clarida et al (2000), the typical empirical model of monetary policy specifies the target for the nominal Federal Funds rate can be written as

$$
\tilde{i}_{t}=i^{*}+\rho_{\pi}\left(E_{t} \pi_{t+p}-\pi^{*}\right)+\rho_{y} E_{t} y_{t+q}
$$

where $\tilde{i}$ is the target nominal interest rate, $i^{*}$ is the equilibrium interest rate, $E_{t} \pi_{t+p}$ is the inflation rate that at time $t$ is expected for time $(\mathrm{t}+\mathrm{p}), \pi^{*}$ is the desired or target inflation rate, $E_{t} y_{t+q}$ is the output gap that at time $t$ is expected for time $(\mathrm{t}+\mathrm{q}), \rho_{\pi}$ is the weight on inflation and $\rho_{y}$ is the weight on output. The adjustment of the actual interest rate towards the target is described by

$$
i_{t}=\rho_{i}(L) i_{t-1}+\left(1-\rho_{i}\right) \tilde{i_{t}}
$$

where $\tilde{i}_{t}$ is given by (1), $\rho_{i}(L)=\rho_{i 1}+\rho_{i 2} L+\ldots+\rho_{i n} L^{n-1}$ and we can use $\rho_{i} \equiv \rho_{i}(1)$ as a measure of interest rate persistence. The implied empirical monetary policy rule is therefore

$$
i_{t}=\rho_{0}+\rho_{i}(L) i_{t-1}+\left(1-\rho_{i}\right)\left\{\rho_{\pi} E_{t} \pi_{t+p}+\rho_{y} E_{t} y_{t+q}\right\}
$$

where $\rho_{0}=\left(1-\rho_{i}\right)\left(i^{*}-\rho_{\pi^{*}} \pi^{*}\right.$. 
Extending the monetary policy rule in (4) to allow for interest rate smoothing, we can write

$$
i_{t}=\rho_{0}+\rho_{i}(L) i_{t-1}+\left(1-\rho_{i}\right)\left\{\rho_{\pi t} E_{t} \pi_{t+p}+\rho_{y t} E_{t} y_{t+q}\right\}
$$

where $\rho_{\pi t}=\rho_{\pi}+\rho_{\pi}^{\pi} \sigma_{\pi t}^{2}+\rho_{\pi}^{y} \sigma_{y t}^{2} \quad$ and $\rho_{y t}=\rho_{y}+\rho_{y}^{\pi} \sigma_{\pi t}^{2}+\rho_{y}^{y} \sigma_{y t}^{2}$. If increased uncertainty leads to a more passive response to a variable, then $\rho_{\pi}^{\pi}<0$ and $\rho_{y}^{y}<0$. If increased uncertainty about one variable strengthens the response to other variables, then $\rho_{\pi}^{y}>0$ and $\rho_{y}^{\pi}>0$.

In (2), aggregate demand depends on the unobserved state of the economy. We therefore substitute (3) into (2):

$$
y_{t}=\theta_{y 0}-\theta_{y} r_{t-k}+\gamma(L) y_{t-1}+\xi_{t}
$$

where $\theta_{y 0}=\alpha_{0} \beta, \theta_{y}=\alpha \beta$ and $\xi_{t}=\beta \varepsilon_{t}+\eta_{t} . \xi$ is a demand shock, assumed to be distributed as $N\left(0, \sigma_{y t}^{2}\right)$. Since the variance of $\xi$ is proportional to that of $\eta$, we assume that this also evolves as a $\operatorname{GARCH}(1,1)$ process, so $\sigma_{y t}^{2}=\phi_{0}+\phi_{1} \xi_{t-1}^{2}+\phi_{2} \sigma_{y t-1}^{2}$ where $\phi_{0}, \quad \phi_{1}$ and $\phi_{2}$ are parameters. We can then use the implied variance of $\xi$ to measure uncertainty about the output gap. Our empirical model comprises equations (1), (8) and (9). 
Our model allows us to quantify the effects of uncertainty on monetary policy. To do this we can construct the counterfactual interest rate, a measure of what the interest rate would have been if there had been no uncertainty, using

$$
i_{t}^{c}=\hat{\rho}_{0}+\hat{\rho}_{i}(L) i_{t-1}+\left(1-\hat{\rho}_{i}\right)\left\{\hat{\rho}_{\pi} E_{t} \pi_{t+p}+\hat{\rho}_{y} E_{t} y_{t+q}\right\}
$$

where $\hat{\rho}_{0}, \hat{\rho}_{i}, \hat{\rho}_{\pi}$ and $\hat{\rho}_{y}$ are estimates of the corresponding parameters in (8). Equation (10) is simply the fitted value of (8) but where $\sigma_{\text {tt }}^{2}=\sigma_{y t}^{2}=0$ for all t. $i_{t}^{c}$ is an estimate of what the interest rate would have been if there had been no uncertainty. We can quantify the effect of uncertainty on monetary policy using $\hat{i}_{t}-i_{t}^{C}$, the gap between the fitted value of the interest rate from estimates of (8) and the counterfactual interest rate, where a positive value of this gap indicates that interest rates were higher because of uncertainty.

\section{3) Empirical Results}

We use quarterly data for 1983Q1-2003Q4. The sample corresponds to the chairmanships of Paul Volcker and Alan Greenspan, but excludes the period when the Federal Reserve targeted non-borrowed reserves, rather than interest rates $^{5}$. We use the Effective Federal Funds rate as the nominal interest rate, inflation is the annual proportional change in the consumer price index and the output gap is the difference between the logarithm of GDP and the logarithm of

\footnotetext{
${ }^{5}$ Rudebusch (1998) points out that it is hard to estimate a stable US policy rule for the whole postwar period.
} 
the Congressional Budget Office measure of potential GDP. Preliminary unit root analysis (the results are not reported but are available on request) showed that the output gap is stationary whereas the order of integration of the interest rate and inflation is more ambiguous; we assume that all variables are stationary (see also Dolado et al, 2004 and Clarida et al, 2000, for a discussion of similar issues).

Estimates of the simple Taylor rule model of monetary policy in (7) are presented in column (i) of Table 2. We find that the data prefer a specification in which interest rates respond to the expected values of inflation and the output gap one quarter ahead and in which use two lags of the interest rate are used to capture the persistence effect. We treat inflation and the output gap as endogenous, replacing expected future variables with actual values and then estimate by GMM using lagged variables as instruments. We estimate that the weight on inflation is 1.58 , that on output is 0.84 and the persistence parameter is 0.96. These estimates, which are comparable to other results in the literature (eg Judd and Rudebusch, 1998, Clarida et al, 2000, Dolado et al, 2004, Castelnuovo, 2003), satisfy the Taylor principle that excessive inflation should trigger increases in the real interest rate. They also indicate a moderately relatively strong response to the output gap (although this effect is insignificant) and show considerable interest rate smoothing. However, as Table 1b shows, the estimates fail the parameter stability test.

We estimated the system comprising equations (1), (8) and (9) for various configurations of the model, considering a range of values for $j, k, p$ and $q$. Our 
preferred model has a contemporaneous response of the output gap to the real interest rate $(k=0)$ and includes two lags of the output gap in (9), whereas inflation responds to the current output gap $(j=0)$ in $(1)$ and interest rates respond to the expected inflation and output gaps one quarter ahead $(p=q=1)$, so the preferred specification of the interest rates equation in our system is the same as that of the simple Taylor rule ${ }^{6}$. Since the conditional variance for inflation and output are generated regressors (see e.g. Pagan, 1984 and Pagan and Ullah, 1988), the estimated variances from equations (1) and (9) may be biased and inconsistent measures of the true level of uncertainty if these equations are misspecified. To check this, we follow Pagan and Ullah (1988) in testing the squared residuals of the estimated GARCH models for neglected serial correlation of up to order 4 .

Column (ii) of Table 1a presents estimates of the system comprising equations (1), (8) and (9), while Table 1b presents measures of goodness of fit and misspecification tests. The estimates of equations (1) and (9) seem sensible. The tests presented in Table $1 \mathrm{~b}$ do not indicate misspecification, suggesting that we may have adequate measures of the conditional heteroscedasticity of inflation and the output gap. The variances of inflation and the output gap implied by the estimates in column (ii) are presented in figure 1.

Our measures of uncertainty, presented in figure 1 seem plausible. Inflation uncertainty is greatest in the early part of the sample, following the change in Fed Chair in 1987, in the early 1990s and after the third quarter of

\footnotetext{
${ }^{6}$ Estimates of these alternative models are similar to those reported in Table 1, except for the case of a purely backward-looking Taylor rule $(p=q=-1)$ where the inflation effect was negative.
} 
2001. Output gap uncertainty declines throughout the 1980 s with resurgences in the early 1990s and after late 1999. The low levels of uncertainty shown in figure 1 in the 1990s reflects the unusual stability of output and inflation in that period that has been noted by, among others, Mankiw (2001).

Estimates of our proposed model of monetary policy under uncertainty in (8) (as part of the system also involving equations (1) and (9)) are presented in column (ii) of Table 2. The inclusion of uncertainty effects improves the fit of the interest rate equation model and the estimates of this equation now pass the parameter stability test. The effects of uncertainty are statistically welldetermined. We find that $\rho_{\pi}^{\pi}<0$ and $\rho_{y}^{y}<0$, indicating that monetary policy is less responsive to inflation and the output gap when these are more uncertain. We also find that $\rho_{\pi}^{y}>0$ and $\rho_{y}^{\pi}>0$, showing that monetary policy is more responsive to one variable when the other is more uncertain. These estimates are consistent with the predictions of the theoretical literature, suggesting that the behavior of policymakers in the face of uncertainty is conforms to these requirements for optimal monetary policy.

We illustrate the impact of uncertainty on interest rates in figure 2, where we plot $\hat{i}_{t}-i_{t}^{C}$, the gap between the fitted and counterfactual interest rates, with estimated confidence intervals of $+/-$ two standard errors $^{7}$. There are three periods in which uncertainty had a significant effect on interest rates: earlymid1983, when uncertainty increased interest rates by $100-140$ basis points,

Full details of these and other unreported estimates are available from the authors. 
1989Q3-1990Q4 when uncertainty increased interest rates by up to 50 basis points and 1996Q1-2001Q1 when uncertainty reduced interest rates by up to 50 basis points over five years.

These are plausible findings. The large effect in 1983 reflects uncertainty about the effects of the switch to the interest rate as the policy instrument and may also reflect continuing uncertainty about change in policy instituted by Paul Volcker a few years earlier; the effect of the early 1990s may reflect the recession of 1990-1, while the sustained effect of the late 1990s reflects the debate about whether the increase in output over the 1990s reflected a rapid increase in the underlying equilibrium level of output (e.g. Gordon, 1997). We can calculate the relative contributions of inflation and output gap uncertainty to the gap between the fitted and counterfactual interest rates using

$$
\hat{i}_{t}-i_{t}^{c}=\left(1-\hat{\rho}_{i}\right)\left\{\left[\hat{\rho}_{\pi}^{\pi} E_{t} \pi_{t+1}+\hat{\rho}_{y}^{\pi} E_{t} y_{t+1}\right] \sigma_{\pi t}^{2}+\left[\hat{\rho}_{\pi}^{y} E_{t} \pi_{t+1}+\hat{\rho}_{y}^{y} E_{t} y_{t+1}\right] \sigma_{y t}^{2}\right\}
$$

Figure 3 depicts the contributions of inflation and output gap uncertainty to the gap between the fitted and counterfactual interest rates, constructed using the decomposition in (11). The gap is more closely correlated with the output gap effect, suggesting that the impact of uncertainty on interest rates is largely driven by output gap uncertainty, which generally outweighs the effect of inflation uncertainty. This is consistent with the comments of policymakers, whose focus

\footnotetext{
${ }^{7}$ Recursive GMM is used to derive recursive estimates and standard errors of the parameters in (8) which are then used to construct $\hat{i}_{t}-i_{t}^{C}+/$ - two standard errors.
} 
is usually on output uncertainty (e.g. Meyer, 1999, Greenspan, 2003, and Yellen, 2003).

Our model assumes that the only effect of uncertainty on monetary policy rules is on the response of the interest rate to inflation and the output gap. We also estimated alternative models of the impact of uncertainty on monetary policy rules. In particular, we added inflation and output gap uncertainty directly to the model in (8), producing a composite model that encompasses both our model and that of Dolado et al (2004) $)^{8}$. The direct effects of inflation and output gap uncertainty were insignificant suggesting that uncertainty only affects monetary policy by changing the response of interest rates to inflation and the output gap ${ }^{9}$.

We also considered models in which uncertainty affects the degree of interest rate smoothing ${ }^{10}$. This was not successful. We also considered an alternative model in which interest rates are affected by asset price disequilibria, measured by the lag of the log(dividend-price ratio) based on the S\&P composite stock price index. As an alternative measure of asset prices, we also considered whether interest rates are affected by the growth of the S\&P index (following

\footnotetext{
${ }^{8}$ The model estimated was $i_{t}=\rho_{0}+\rho_{i}(L) i_{t-1}+\left(1-\rho_{i}\right)\left\{\rho_{\pi t} E_{t} \pi_{t+1}+\rho_{y t} E_{t} y_{t+1}+\rho_{\sigma_{\pi}} \sigma_{\pi t}^{2}+\rho_{\sigma_{y}} \sigma_{y t}^{2}\right\}$; this model simplifies to the model in Dolado et al (2004) if $\rho_{\pi}^{\pi}=\rho_{\pi}^{y}=\rho_{y}^{\pi}=\rho_{y}^{y}=0$.

${ }^{9}$ We could not reject the restrictions $\rho_{\sigma_{\pi}}=0$ and $\rho_{\sigma_{y}}=0$ but could reject the restrictions $\rho_{\pi}^{\pi}=\rho_{\pi}^{y}=\rho_{y}^{\pi}=\rho_{y}^{y}=0$.

10 The model estimated was $i_{t}=\rho_{0}+\rho_{i t}(L) i_{t-1}+\left(1-\rho_{i t}\right)\left\{\rho_{\pi t} E_{t} \pi_{t+1}+\rho_{y t} E_{t} y_{t+1}\right\}$, where $\rho_{i t}(L)=\rho_{i 1 t}+\rho_{i 2 t} L+\ldots+\rho_{\text {int }} L^{n-1}$ and $\rho_{i j t}=\rho_{i j}+\rho_{i j}^{\pi} \sigma_{\pi t}^{2}+\rho_{i j}^{y} \sigma_{y t}^{2}, j=1, \ldots$, n. If policymakers adjust interest rates less frequently when uncertainty is greater (eg, Goodhart, 1999) then $\rho_{i j}^{\pi}>0$ and $\rho_{i j}^{y}>0$.
} 
Bernanke and Gertler, 1999, 2001). Consistent with Bernanke and Gertler (1999), we failed to find any effect.

We performed a number of robustness checks. We estimated our system using two alternative volatility measures, (i) derived from recursive estimates of our GARCH systems and (ii) measured as a four quarter backward-looking moving average of the measures derived from the estimates of Table 1 . We also used alternative measures of the output gap, obtained by (i) applying the Kalman Filter to our measure of the output gap, regressing the log of output on its lag and the unobserved state variable, assuming that the latter follows a random walk, (ii) using the Hodrick-Prescott filtered level of output as a measure of potential output and (iii) using real-time output data from the database maintained by the Federal Reserve Bank of Philadelphia. A measure of the real-time output gap was constructed by applying the Hodrick-Prescott filter to the real-time output to obtain a measure of potential real-time output. We also estimated our system using a measure of the average real interest rate, constructed as the difference between a four quarter moving average of the nominal interest rate and a four quarter moving average of the inflation rate (see Rudebusch, 2001). Table 2 summarises the average weights on inflation and the output gap implied by these estimates and the correlations between the implied values of $\rho_{\pi t}$ and $\rho_{y t}$ and those implied by the estimates of (8). In most cases, the average weights on inflation and the output gap are similar to those in Table 1, with correspondingly high correlations. 


\section{4) Conclusions}

This paper has argued that the effects of uncertainty about the true state of the economy can be analyzed using a simple 3-equation system that captures the main features of the theoretical literature on optimal monetary policy in this case. The system features a monetary policy rule that extends the familiar Taylor rule representation of monetary policy by allowing the weights on inflation and the output gap to depend on the variances of inflation and the output gap, these latter being derived from GARCH models. Estimating our model using data since the early 1980s, we have found that the actions of policymakers are consistent with the principles of optimal policy in that they respond less vigorously to inflation and the output gap when these are less certain. They also respond more strongly to one variable when the other is more uncertain.

We have used our model to calculate the counterfactual interest rate that our estimates suggest would have been observed if there had been no uncertainty. Using this, we found that uncertainty has a marked impact on monetary policy in three periods. We find that uncertainty increased interest rates following the switch to the interest rate as the tool of policy in the early 1980 s and during the recession of the early 1990s, but that uncertainty reduced interest rates during the long expansion of the mid- late 1990s, when debate concerned the sustainability of high output growth.

Our findings suggest that the effects of uncertainty can be detected using simple empirical models of monetary policy rules. Our work can be extended in several ways. We might embed on analysis of monetary policy in a more 
sophisticated structural model in order to estimate the parameters of a structural model of optimal monetary policy. We might estimate our model over different time periods in order to identify occasions when the behavior of policymakers was not consistent with the predictions of models of optimal monetary policy. We might estimate our model using data for different countries in order to investigate the impact of different monetary policy regimes on the response to uncertainty. We intend to address these issues in future work. 


\section{Table 1}

\section{Model estimates using GMM. Sample: 1983Q1-2003Q4}

Interest rate equation: $i_{t}=\rho_{0}+\rho_{i}(L) i_{t-1}+\left(1-\rho_{i}\right)\left\{\rho_{\pi t} E_{t} \pi_{t+1}+\rho_{y t} E_{t} y_{t+1}\right\}$, where

$$
\rho_{\pi t}=\rho_{\pi}+\rho_{\pi}^{\pi} \sigma_{\pi t}^{2}+\rho_{\pi}^{y} \sigma_{y t}^{2} \quad \text { and } \rho_{y t}=\rho_{y}+\rho_{y}^{\pi} \sigma_{\pi t}^{2}+\rho_{y}^{y} \sigma_{y t}^{2} .
$$

Output gap equation: $y_{t}=\theta_{y 0}-\theta_{y} r_{t}+\gamma_{1} y_{t-1}+\gamma_{2} y_{t-2}+\xi_{t}, \quad \sigma_{y t}^{2}=\phi_{0}+\phi_{1} \xi_{t-1}^{2}+\phi_{2} \sigma_{y t-1}^{2}$. Inflation equation: $\pi_{t}=\pi_{t-1}+\theta_{\pi} y_{t}+v_{t}, \quad \sigma_{\pi t}^{2}=\omega_{0}+\omega_{1} v_{t-1}^{2}+\omega_{2} \sigma_{\pi t-1}^{2}$.

\section{a) parameter estimates}

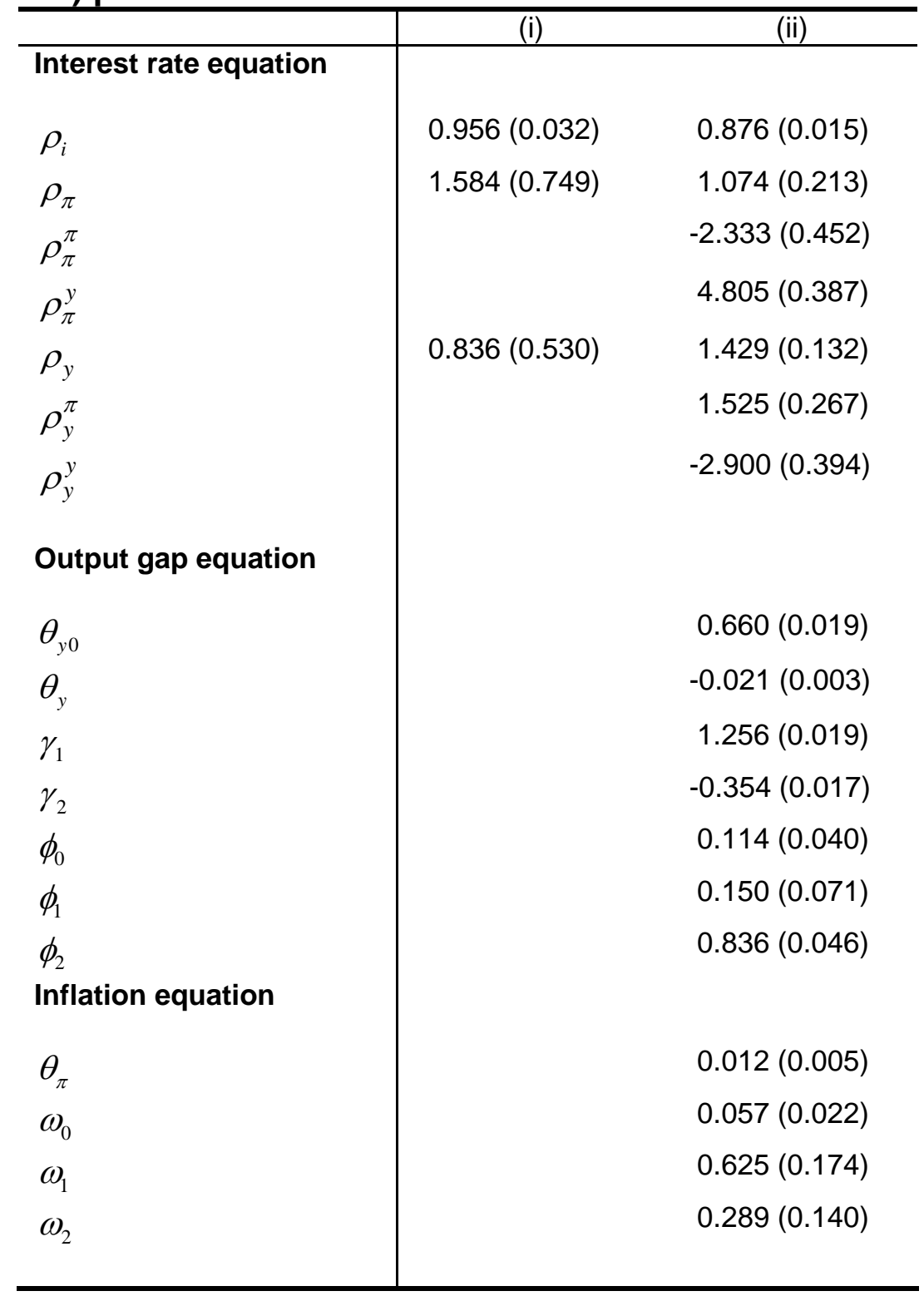

Notes: Column (i) reports the parameter estimates of equation (7) in main text. Column (ii) report the parameter estimates of the system involving equations (1), (8) and (9) in main text. Numbers in parentheses are the standard errors of the estimates. 
b) Goodness of fit and diagnostics

\begin{tabular}{|c|c|c|}
\hline & (i) & (ii) \\
\hline Interest rate equation & & \\
\hline Average inflation effect & 1.584 & 2.312 \\
\hline Average output gap effect & 0.836 & 0.720 \\
\hline Adjust. $\mathrm{R}^{2}$ & 0.961 & 0.964 \\
\hline s.e. of regression & 0.471 & 0.451 \\
\hline $\mathrm{J}$ stat & $11.00[0.81]$ & $17.99[0.12]$ \\
\hline Parameter stability & $2.11[0.03]$ & $0.15[0.97]$ \\
\hline \multicolumn{3}{|l|}{ Output gap equation } \\
\hline Adjust. $\mathrm{R}^{2}$ & & 0.943 \\
\hline s.e. of regression & & 0.493 \\
\hline Parameter stability & & $0.14[0.93]$ \\
\hline Neglected ARCH & & $0.50[0.73]$ \\
\hline \multicolumn{3}{|l|}{ Inflation equation } \\
\hline Adjust. $\mathrm{R}^{2}$ & & 0.782 \\
\hline s.e. of regression & & 0.495 \\
\hline Parameter stability & & $1.62[0.20]$ \\
\hline Neglected ARCH & & $0.68[0.60]$ \\
\hline \multicolumn{3}{|c|}{$\begin{array}{l}\text { Jotes: For column (i), J stat is a chi-square test of the model's } \\
\text { veridentifying restrictions (Hansen, 1982). For column (ii), J stat is a chi- } \\
\text { quare test of the system's overidentifying restrictions. The instruments } \\
\text { are a constant, one lag of } \sigma_{y t}^{2} \text { and } \sigma_{\pi t}^{2} \text { and six lags of the interest rate, } \\
\text { nflation and the output gap. Parameter stability is an } F \text { test of parameter } \\
\text { tability (see Lin and Teräsvirta, 1994, and Eitrheim and Teräsvirta, } \\
996 \text { ). Neglected ARCH is the Lagrange Multiplier F test on the squared } \\
\text { esiduals for remaining serial correlation of order } 4 \text {. Numbers in square } \\
\text { rackets are the probability values of the test statistics. }\end{array}$} \\
\hline
\end{tabular}




\section{Table 2}

\section{Estimates based on alternatives measures}

\begin{tabular}{|l|l|l|l|l|l|l|}
\hline & $\begin{array}{l}\text { Recursive } \\
\text { estimates }\end{array}$ & $\begin{array}{l}\text { 4-quarter } \\
\text { MA } \\
\text { estimates }\end{array}$ & $\begin{array}{l}\text { Kalman } \\
\text { Filter } \\
\text { estimates }\end{array}$ & $\begin{array}{l}\text { Hodrick- } \\
\text { Prescott } \\
\text { Filter } \\
\text { estimates }\end{array}$ & $\begin{array}{l}\text { Real-time } \\
\text { output } \\
\text { estimates }\end{array}$ & $\begin{array}{l}\text { Average } \\
\text { real interest } \\
\text { rate } \\
\text { estimates }\end{array}$ \\
\hline $\begin{array}{l}\text { Average } \\
\text { inflation effect }\end{array}$ & 2.326 & 1.849 & 1.300 & 1.232 & 1.452 & 1.836 \\
\hline Correlation $^{1}$ & 0.715 & 0.473 & 0.814 & 0.956 & 0.556 & 0.962 \\
\hline & & & & & & 1.938 \\
\hline $\begin{array}{l}\text { Average output } \\
\text { gap effect }\end{array}$ & 0.953 & 0.273 & 0.681 & 1.809 & 0.958 \\
\hline Correlation $^{2}$ & 0.708 & 0.561 & 0.959 & 0.868 & 0.554 & 0.635 \\
\hline
\end{tabular}

Notes:

${ }^{1}$ Correlation between the implied values of $\rho_{\pi t}=\rho_{\pi}+\rho_{\pi}^{\pi} \sigma_{\pi t}^{2}+\rho_{\pi}^{y} \sigma_{y t}^{2}$ and that implied by the estimate of Table 1 column (ii).

${ }^{2}$ Correlation between the implied values of $\rho_{y t}=\rho_{y}+\rho_{y}^{\pi} \sigma_{\pi t}^{2}+\rho_{y}^{y} \sigma_{y t}^{2}$ and that implied by the estimate of Table 1 column (ii).

${ }^{3}$ The average real interest rate is the difference between $\bar{i}_{t}$ and $\bar{\pi}_{t}$, where $\bar{i}_{t}$ and $\bar{\pi}_{t}$ are the four quarter moving averages of the nominal interest and inflation rates respectively. 
Figure 1

The implied variance of inflation and the output gap

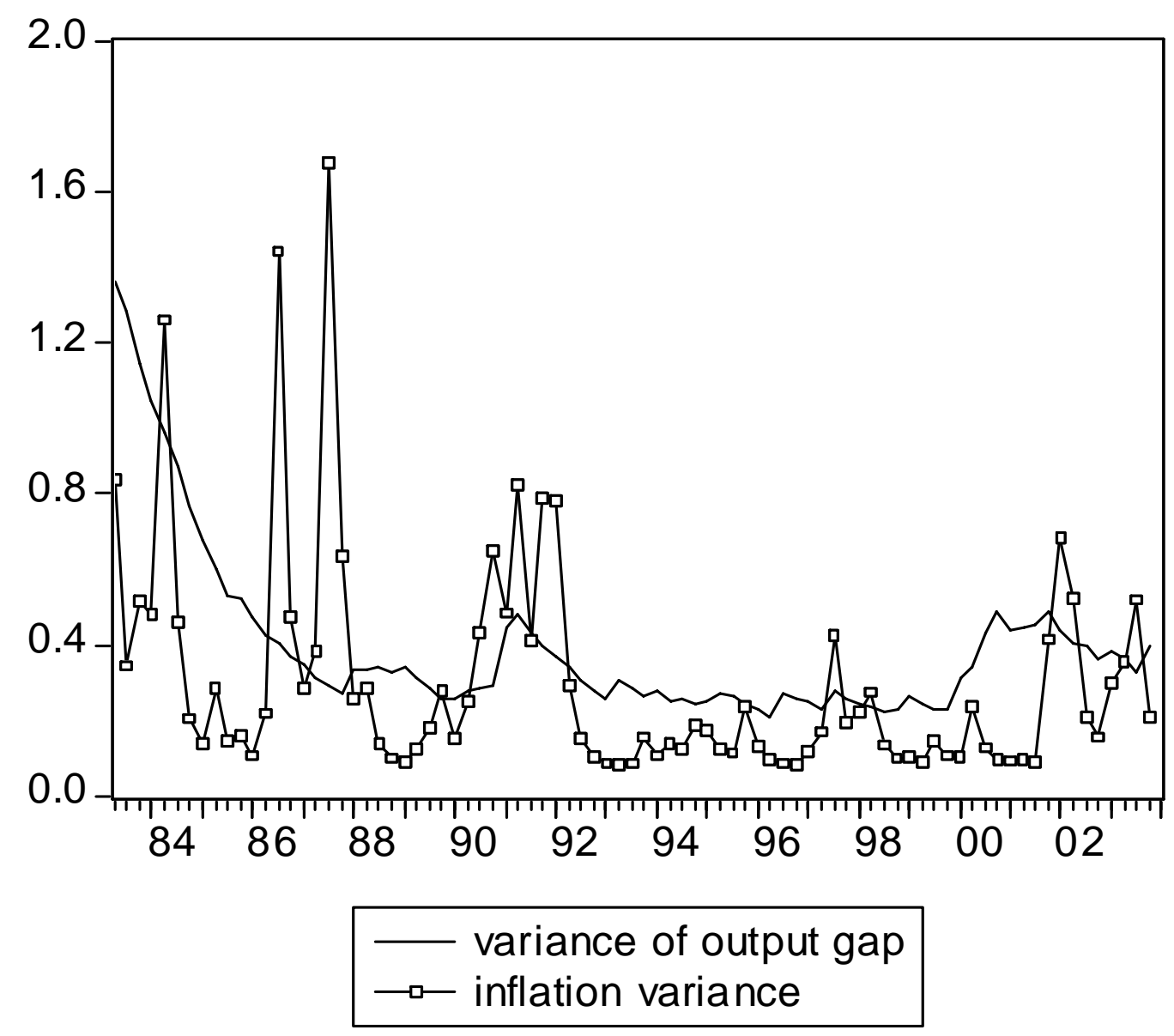


Figure 2

The gap between fitted and counterfactual interest rates

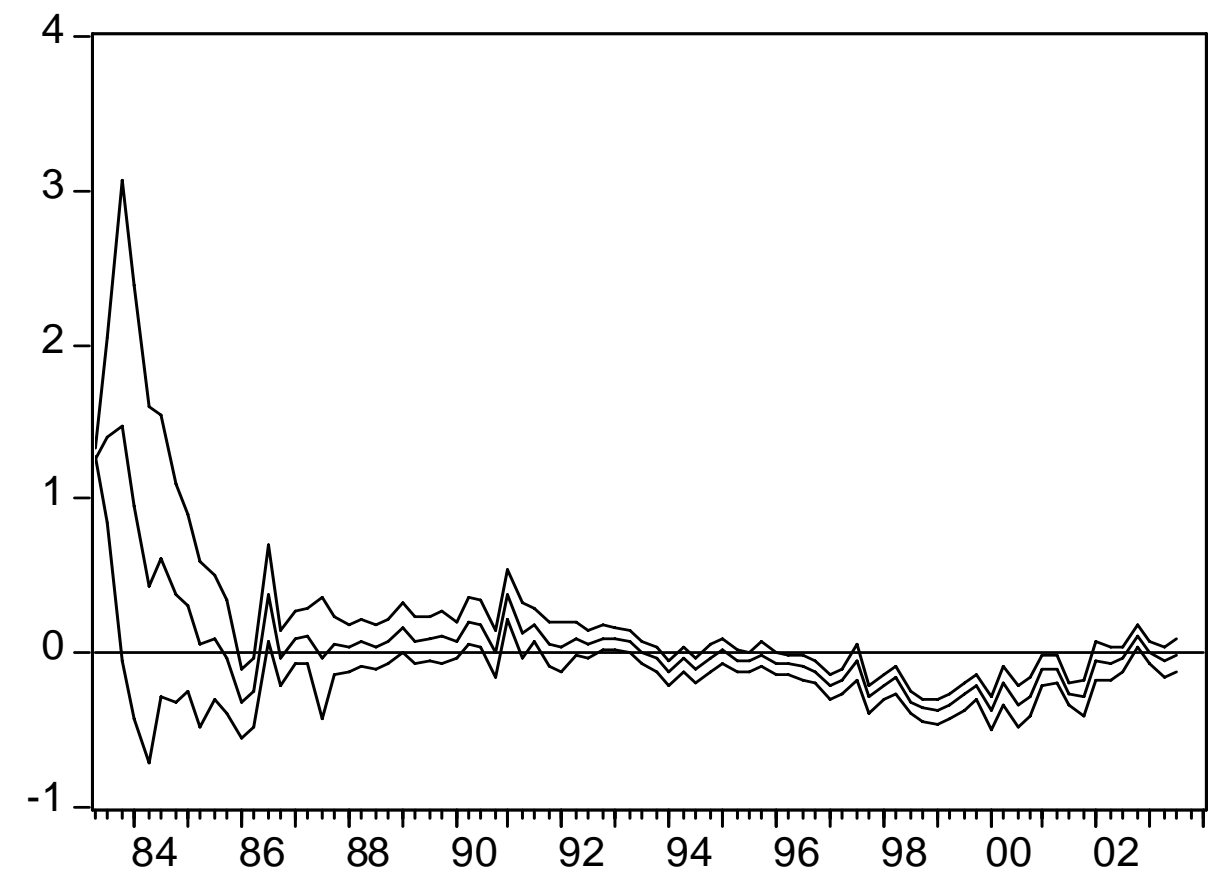

gap between fitted and counterfactual interest rates plus/minus $2{ }^{*}$ se 
Figure 3

The contributions of inflation and output gap uncertainty to the gap between fitted and counterfactual interest rates

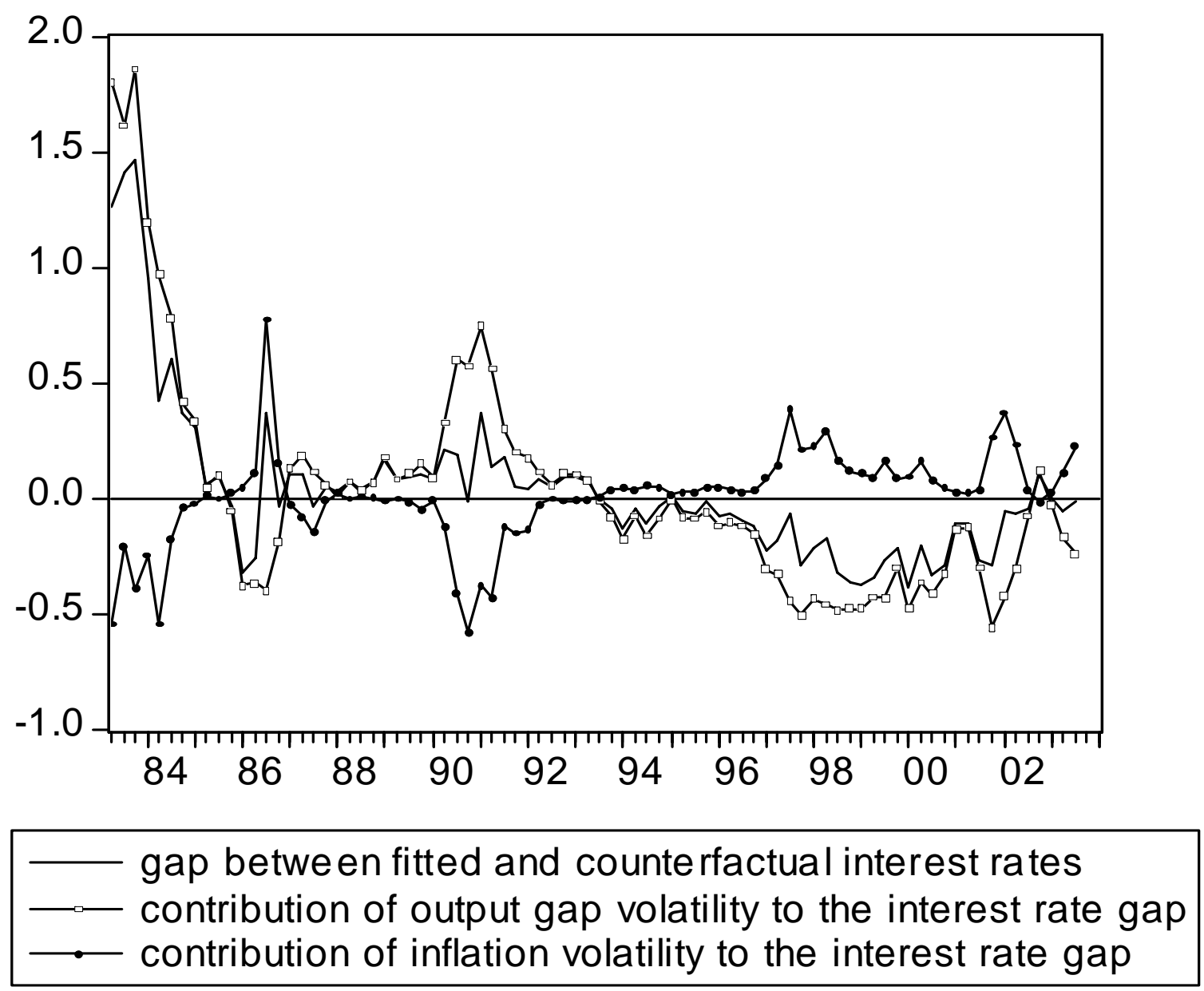




\section{References}

Bernanke, B.S. and M. Gertler (1999). Monetary policy and asset price volatility, Federal Reserve Bank of Kansas City Economic Review, 84, pp 17-51.

Bernanke, B.S. and M. Gertler (2001). Should central banks respond to movements in asset prices? American Economic Review Papers and Proceedings, 91, pp 253-257.

Brainard, W. (1967). Uncertainty and the effectiveness of policy, American Economic Review, 57, pp 411-425.

Castelnuovo, E. (2003). Taylor rules, omitted variables and interest rate smoothing in the US, Economics Letters, 81, pp 55-59.

Clarida, R. J., M. Gali and M. Gertler (2000). Monetary policy rules and macroeconomic stability: evidence and some theory, Quarterly Journal of Economics, 115, pp 147-180.

Dolado, J., R. María Dolores and F.J. Ruge-Murcia (2004). Non-linear monetary policy rules: Some new evidence for the US, Studies in Nonlinear Dynamics and Econometrics, 8, article 2.

Eitrheim, $\varnothing$. and T. Teräsvirta (1996). Testing the adequacy of smooth transition autoregressive models, Journal of Econometrics, 74, pp 59-75.

Goodhart, C. (1999). Central Bankers and Uncertainty, Bank of England Quarterly Review, February, pp 102-121.

Gordon, R.J. (1997). The time-varying NAIRU, and its Implications for economic policy, Journal of Economic Perspectives, 11, pp 11-32.

Greenspan, A. (2003). Remarks, in Monetary Policy and Uncertainty: Adapting to a Changing Economy, Federal Reserve Bank of Kansas City.

Grier, K. and M. Perry (2000). The Effects of Real and Nominal Uncertainty on Inflation and Output Growth: Some GARCH-M Evidence, Journal of Applied Econometrics, 15, pp 45-58

Hansen, L. P. (1982). Large sample properties of generalized method of moments estimators, Econometrica, 82, pp 1029-1054.

Hodrick, R.J. and E.C. Prescott (1997). Postwar U.S. business cycles: An empirical investigation, Journal of Money, Credit, and Banking, 29, pp 1-16. 
Judd, J. and G. Rudebusch (1998). Taylor's rule and the Fed: 1970-97, Federal Reserve Bank of San Francisco Economic Review, 3, pp 3-16.

Lin, C-F.J. and T. Teräsvirta (1994). Testing the constancy of regression parameters against continuous structural change, Journal of Econometrics, 62, pp 211-228.

Mankiw, G (2001). American Economic Policy in the 1990s, Centre for Business and Government, John F Kennedy School of Government, Harvard.

Meyer, L. (1999). Q\&A on the economic outlook and challenged facing monetary policy, speech before the Philadelphia Council for Business Economics, www.federalreserve.gov

Pagan, A. (1984). Econometric issues in the analysis of regressions with generated regressors, International Economic Review, 25, pp 221-247.

Pagan, A. and A. Ullah (1988). The econometric analysis of models with risk terms, Journal of Applied Econometrics, 3, pp 87-105.

Peersman, G. and F. Smets (1999). The Taylor Rule: a useful monetary policy benchmark for the Euro Area? International Finance, 2, pp 85-116.

Rudebusch, G. (2001). Is the Fed too timid? Monetary policy in an uncertain world, Review of Economics and Statistics, 88, pp 203-17.

Rudebusch, G. (1998). Do measures of monetary policy in a VAR make sense?, International Economic Review, 39, pp 907-931.

Sack, B. (2000). Does the Fed act gradually? A VAR analysis, Journal of Monetary Economics, 46, pp 229-256.

Smets, F. (2002). Output gap uncertainty: does it matter for the Taylor Rule?, Empirical Economics, 27, pp 113-129.

Soderstrom, U. (2002). Monetary policy with uncertain parameters, Scandinavian Journal of Economics, 104, pp 125-145.

Srour, G. (2003). Some notes on monetary policy rules with uncertainty, Bank of Canada Working Paper No. 2003-16.

Svensson L.E.O. and M. Woodford (2003). Indicator variables for optimal policy, Journal of Monetary Economics, 50, pp 691-720. 
Svensson L.E.O. and M. Woodford (2004). Indicator variables for optimal policy under asymmetric information, Journal of Economic Dynamics and Control, 28, pp 661-690.

Swanson, E. (2004). On signal extraction and non-certainty-equivalence in optimal monetary policy rules, Macroeconomic Dynamics, 8, pp 27-50.

Taylor, J. (1993). Discretion versus policy rules in practice, Carnegie-Rochester Conference Series on Public Policy, 39, pp 195-214.

Walsh, C. (2004). Implications of a changing economic structure for the strategy of monetary policy, Santa Cruz Center for International Economics Working Paper No. 03/18, University of California, Santa Cruz.

Woodford, M. (2003), Interest and Prices: Foundations of a Theory of Monetary Policy, Princeton: Princeton University Press.

Yellen, J. (2003). Remarks, in Monetary Policy and Uncertainty: Adapting to a Changing Economy, Federal Reserve Bank of Kansas City. 